ISSN: 1838-3815 (online) Journal Homepage: https://ojs.deakin.edu.au/index.php/itlge/

\title{
Provocation
}

Subject to Editor review, Provocations are intended to be short and showcase thought, leadership and expert commentary on the future of credentials for work in a disrupted world.

\section{Making micro-credentials work: A student perspective}

\author{
Kaleb Oxley ${ }^{1}$ and Tristan van Rooyen ${ }^{2}$ \\ Corresponding author: Kaleb Oxley: (oxleyk@deakin.edu.au) \\ ${ }^{1}$ Graduate of Faculty of Law, Deakin University, Student of School of Engineering RMIT, Victoria, Australia. \\ ORCID: 0000-0002-1587-0282 \\ ${ }^{2}$ Student of Faculties of Law and Science, Deakin University, Victoria, Australia. ORCID: 0000-0001-9721-8652
}

Micro-credentials, digital badges and industry-recognised certificates have been attracting considerable attention in recent years and with the disruption of many jobs due to the pandemic, interest in continuing education has grown. Micro-credentials represent an alternative approach to career and professional development (Ghasia, Machumu, \& De Smet, 2019, p. 219; LaMagna, 2017, p. 207). These credentialed ... industry aligned short units of learning' are described by Wheelahan \& Moodie (2021, p. 212) as an extension of '21st century skills' and the discourse of employability in higher education. Graduate employability has become heavily integrated into modern higher education policy frameworks, but what does this actually mean from a student perspective? Bernstein (2000) has critiqued micro-credentials as being too generic. In real terms, what do students serve to gain from this so called 'genericism'? How does subjecting individuals to a perpetual 'trainability', divorced from [their] core disciplinary or occupational focus (Wheelahan \& Moodie, 2021, p. 212) not detract from the intended mastery of the skills concerned? If the possibility to enhance skills ... [and] add practicality in the academic content, set forth by Ghasia et al. $(2019$, p. 219), are to value-add to what should be a student-oriented space, a more targeted approach is needed. We propose that micro-credentials should be standardised across the higher education sector, incentivised and devised, with student input. This would ensure recognition of the academic context in which they are embedded, and the target audience for whom they are designed. Micro-credentials should be relevant to all aspects of employability, including skills relevant to the academic context, and focus on creating a well-rounded graduate.

\section{An inconsistent approach to micro-credentials}

As students enrolled in double undergraduate degrees across two institutions, we have witnessed the divergent and 'variable' approach to the micro-credential infrastructure and its implementation, considered by Stefaniak \& Carey (2019). The absence of a consistent and universal approach is attributable to varying institutional goals and program objectives. We argue for a different approach, 
one that establishes a more harmonised framework that can be readily adopted by all universities. At one institution, we experienced a renascent, all-encompassing approach that promotes a wide uptake in credential usage, both intra and extra-curricular. This would appear consistent with Ralston's (2021) consideration of the 'microcredentialing craze' and reflect a desire to repurpose higher education as a delivery method for vocational education (pp. 83-84, 88). In this vein, there is some attempt to integrate an 'award of credits' towards satisfying a degree, such as $5-10 \%$ of a unit score satisfied by completing a micro-credential relevant to the unit learning objectives (Ralston, 2021, p. 85). This could be seen as an attempt at the 'stacking' methodology applied in other jurisdictions to the intention being, according to Williamson and Pittinsky (2016), to increase students' currency in a knowledge economy, with the end goal of yielding better jobs and higher wages. Nonetheless, in contrast to the higher education degree proper, micro-credentials appear to place emphasis on applied knowledge or vocational training, for the sake of meeting employer's workforce needs (Ralston, 2021, citing Craig, 2015, p. 85).

At our other institution, a more bespoke program design appears to award students for excellence in university-wide areas of achievement, that reflect key attributes of professional development relevant to the workforce. This model recognises refined, pre-existing or developed, skillsets and awards on individual merit, in contrast to creating new skills and offering students the opportunity to 'stack' knowledge capital and currency. In both cases, the variable approach seems to have missed the mark in terms of recognising what students require to succeed. Neither approach addresses how gaps in undergraduate skillsets translate to employment outcomes. We recommend that microcredentialising core graduate capabilities, embedding these into coursework and rewarding or incentivising students with nominal grades (such as $5-10 \%$ of the mark for a unit) would be an appropriate solution.

\section{The gap in micro-credential offerings}

The conversation surrounding employability is ever centric around the needs of the employer. As pointed out by Ralston (2021), micro-credentials are being driven by the strategic human resource directives of large companies (p. 87). Accordingly, as Wheelahan and Moodie (2021) observe, a pervasive and long-standing policy focus surrounding so-called generic and employability skills in vocational education and ... graduate attributes in higher education, could be a mere attempt at 'dressing' these up as '21st century skills' (p.216). These policies may give labour market and economy needs preferential treatment, at the expense of education. The overriding goal of educational policy should not focus strictly on an individual's capacity to be 'market' ready (Wheelahan \& Moodie, 2021). There are basic shortcomings present in higher education settings, reflected in academic skillsets, such as research and group work, and incentives for students to overcome these. At what point do student needs and perspectives shift to the foreground of this conversation?

Deficiencies in basic academic research, formatting and report writing, coupled with inexperienced and undisciplined approaches to group assessment settings are common concerns for undergraduate students. This perspective can be readily gained from students and markers alike. It can be argued that these core aptitudes are of themselves transferrable and indicative of work-ready skills or 'graduate outcomes' at a fundamental level. Assessment of these soft skills impact on academic achievement and correlate with a graduate's capacity to function in a workplace setting. Teamwork, coupled with written and verbal communication skills are key aptitudes sought after in graduate employment. Students require these illustrative skills, at a minimum, to land a graduate job, according to Dr Jaynes of Deakin University (n.d). Grades and academic results are themselves a measure of a candidate's employability. Consequently, micro-credential offerings must be considered against how universally accessible, targeted and relevant they are towards actually enhancing skills that add practicality in the academic context that Ghasia et al. (2019) describe. If students underperform academically, can it be reasoned that this transference of soft skills will allow them to succeed in the labour market? As Ralston (2021) saliently observes, [t]here is a serious mismatch between degrees and what people actually need to launch or advance [a] career ( $p .88)$.

Oxley, K., \& van Rooyen, T. (2021). Making micro-credentials work: A student perspective. Journal of Teaching and Learning for Graduate Employability, 12(1), 44-47. 
The recent higher education trend in zero credit point academic integrity and career and employability modules appears to be missing the mark in addressing core skills of undergraduate students. Zero credit point units are hurdle requirements in foundational skills that do not contribute to a grade point average. To make matters worse, students are neither motivated, nor incentivised to complete modules that offer neither academic reward, nor recognise achievement in the areas impacting their academic bottom line. In the very least, under the Ralston (2021) approach to micro-credential offerings, there appears a limited offering of badges that address the core deficits in academic progress and achievement, which would concurrently serve to demonstrate the 'market' model of an individual's graduate employability, so described by Wheelahan and Moodie (2021). Adapting microcredentials to enhance skills practical to the academic context will both incentivise students and improve academic outcomes. This may serve to repurpose the present approach to one considering what students genuinely want and need in practical terms. Futhermore, the university, as institutional stakeholder, would clearly benefit directly from a higher calibre of student achievement.

Substantively, we propose a multi-faceted approach that acknowledges the potential uses for microcredentials to reward and incentivise students. The current approach does not account for understanding what students actually need or are driven by. Institutions cannot claim that graduate employability or job readiness is an achieved graduate learning outcome on the basis of students failing assessments because of deficits in core academic skills. Conceptually, student input into the design and integration process of micro-credential creation must be embedded, to promote uptake and program longevity and 'maximize buy in' (Stefaniak \& Carey 2019). The authors deduce that a program must align purpose and value. Accordingly, the process should adequately convey 'internal and external value', within academia and its transferability to the job market, against a 'comprehensible purpose', such as improved academic progress. At first blush, this appears to validate the student perspective against underlying issues with skill deficiencies in the academic context. Improved grades and greater ease navigating through the assessment process would be highly regarded by students. The policy-oriented discourse on micro-credentials in jurisdictions such as the EU and UK, sets out a clear framework, harmonising an integrated and universal approach across the higher education sector (Orr, Pupinis, \& Kirdulyte, 2020; QAA, 2021). It focusses on the practical benefits derived by students, as well as industry outcomes. It can, therefore, be reasoned, that taking a practical and academically focused approach to micro-credentials would unilaterally appeal to all three key stakeholders party to the academic transaction: the student or alumni, the institution and the employer.

\section{References}

Bernstein, B. (2000). Pedagogy, symbolic control and identity (2nd ed.). Rowman \& Littlefield Publishers Inc.

Ghasia, M., Machumu, H., \& DeSmet, E. (2019). Micro-credentials in higher education institutions: An exploratory study of its place in Tanzania. International Journal of Education and Development using Information and Communication Technology (IJEDICT), 15(1), 219-230.

Jaynes, S. (n.d.). Six skills you need to land a graduate job. this: Deakin University. https://this.deakin.edu.au/career/six-skills-you-need-to-land-a-graduate-job

LaMagna, M. (2017). Placing digital badges and micro-credentials in context. Journal of Electronic Resources Librarianship, 29(4), 206-210. https://doi.org/10.1080/1941126X.2017.1378538

Orr, D., Pupinis, M., \& Kirdulytè, G. (2020). Towards a European approach to micro-credentials: A study of practices and commonalities in offering micro-credentials in European higher education (Report No. NC03-20-553-EN-N). NESET. https://ec.europa.eu/education/sites/default/files/document-librarydocs/towards-european-approach-micro-credentials-analytical-report.pdf

The Quality Assurance Agency for Higher Education (QAA). (2021, April 16). Which way for micro-credentials? https://www.qaa.ac.uk/docs/qaa/news/quality-compass-which-way-for-microcredentials.pdf?sfvrsn $=25 c 6 d 481 \_8$ 
Ralston, S.J. (2020). Higher education's microcredentialing craze: A postdigital-Deweyan critique. Postdigital Science and Education, 3, 83-101. https://doi.org/10.1007/s42438-020-00121-8

Stefaniak, J., \& Carey, K. (2019). Instilling purpose and value in the implementation of digital badges in higher education. International Journal of Educational Technology in Higher Education, 16(44), 1-21. https://doi.org/10.1186/s41239-019-0175-9

Wheelahan, L., \& Moodie, G. (2021). Analysing micro-credentials in higher education: A Bernsteinian analysis. Journal of Curriculum Studies, 53(2), 212-228. https://doi.org/10.1080/00220272.2021.1887358

Williamson, J., \& Pittinsky, M. (2016, May 23). Making credentials matter. Inside Higher Ed. https://www.insidehighered.com/views/2016/05/23/understanding-differences-what-credentials-arebeing-stacked-and-why-essay 